\title{
Relation between family performance indices and incidence risk of myocardial infarction
}

\begin{abstract}
Aim: The present study aims to determine the relation between family performance indices (cohesion, expressiveness, and conflict) and the risk of myocardial infarction.

Background:Cardiovascular diseases, especially myocardial infarction, is the first factor of fatality in the world and also in Iran. The etiology of myocardial in fraction is a very complicated. One of the risk factors overlooked in the studies associated with the etiology of cardiovascular disorders is family and performance indices of the family.
\end{abstract}

Method: The present research was conducted by a case-control cross-sectional design. The data were collected from two groups, a group of 50 patients with myocardial infarction symptoms (the case group) referring to Heshmat Specialized Hospital for Cardiology in Rasht and Tehran Specialized Heart Center, and a group of 50 healthy persons (control group) with no symptoms of myocardial infarction. The data gathering tool included Family Relationships Index. The data were analyzed by SPSS version 16 using MANOVA method.

Findings: There was a statistically significant difference between case and control groups in terms of control variables history of myocardial infarction, education, history of smoking, history of cholesterol and hypertension $(p<0.01)$, and history of diabetes $(p<0.05)$. There was also a statistically significant difference between groups in terms of cohesion, and conflict indices $(\mathrm{p}<0.01)$.

Conclusion: Deficiency in family performance indices, including cohesion, and conflict in family relationships, are among the main risk factors of myocardial infarction. Therefore, it is necessary to prepare and implement social, behavioral and educational interventions in order to prevent negative effects of inadequacies in family performance indices.

Keywords: family performance indices, myocardial infarction, conflict, expressiveness, cohesiona
Volume II Issue 3 - 2018

Arash Farahani
Master of Sociology, Iran

Correspondence: Arash Farahani, Master of Sociology, Iran, Tehran, Email farahani.ara6@gmail.com

Received: February 07, 2018| Published: June 06, 2018

\section{Introduction}

Official statistics in Iran and the world show that cardiovascular disease (CVD) is the first cause of death. About 50 million people die every year, of which more than 11 million have been infected with cardiovascular disease. Separately in Iran, in 2012, more than 58 percent of deaths were due to cardiovascular disease. ${ }^{1}$ Myocardial infarction (MI), as the most deadly heart disease in cardiovascular disease, is permanent and irreversible cell death and death in the part of the heart muscle (myocardium) due to the onset of a severe ischemia and loss of Blood flow occurs in that part of the heart. ${ }^{2}$ An important point to note here is that 80 percent of early deaths due to cardiovascular disease can be prevented. ${ }^{3}$

The etiology of myocardial infarction is very complicated. To understand and cure this disease, solutions are often centered around medical biomedical paradigms and are less concerned with the social and preventive approach. Myocardial infarction is usually divided into two categories of uncontrollable risk factors (conditions that individuals cannot control, such as inheritance, age, gender) and modifiable risk factors (factors that people can control, such as Lifestyle or personal habits, stress, physical inactivity). ${ }^{4}$ According to one view, health and disease are largely in terms of quantity. The quality of the relations that people have with others is changing. ${ }^{5}$

The factors contributing little attention to the etiology of coronary heart disease are the impact of family factors, including family functioning. It should be noted that failure of family functioning can lead to serious injuries in people's lives, including the occurrence of diseases. Some studies have shown that physical or psychological disorders are the result of pathological forms of family relationships. ${ }^{6}$ Family performance, which is in fact a collaborative effort to maintain and maintain a family balance, can lead to a readiness for members to tolerate family failures. ${ }^{7}$

According to Olson and Barnes, family relations are related to the relation between parents and their children. Family function is defined in terms of three indicators of cohesion, conflict and expressiveness. Coherence is the emotional bond that family members have toward each other. Contradiction, as a disagreement and family incompatibility, may emerge from a simple discontent. Expression based on the definition of psychopathology is considered the degree and severity of internal feelings of individuals, and the amount and manner of their expression, despite the close proximity of the effects the inner afflictions. ${ }^{8}$ 
Consiedring to the results of studies that have been conducted to evaluate in relation between family function and coronary artery disease (CAD), the severity of stress is due to failure in family relations or negative emotional conflicts and family intolerance with these disorders. ${ }^{9}$ Also, some studies have shown that there is a relation between a family status disorder, for example, the existence of a mental stress and its effect on hormonal disorders leading to coronary artery disease. ${ }^{10}$ It has also been shown that the risk of heart disease, especially in women, is reduced by the fall of psychological factors such as negative emotions, anxiety and stress in family members. ${ }^{11}$ Most studies in Iran have led to the recognition of myocardial infarction based on the medical and clinical biology paradigm. Meanwhile, the importance of family-related components, and in particular family function, has become less important than the violation. The aim of this study was to investigate the relation between family functioning indices and the risk of myocardial infarction.

\section{Materials and methods}

This case-control study was conducted in August 2014. In the project, 50 patients were randomly selected between the patients with symptoms of myocardial infarction (AMI), including outpatients and adolescents who had been referred to the specialized centers of cardiology of Heshmat Rasht and specialized center of Tehran Heart. Randomized stratified control trials based on the list of patients referring to the two centers and selected in the case group. To form the control group, 50 healthy people (people without symptoms of coronary artery disease) were randomly selected from the normal population in Rasht and Tehran. The inclusion criteria for the case group, including cardiac function impairment and the presence of coronary artery atherosclerosis, which were the results of left and right arteries on the heart and arteriosclerosis, leading to myocardial infarction. The inclusion criteria for the control group included a lack of clinical signs of coronary artery disease and no heart attack.

Demographic characteristics (age, sex, education, income, history of stroke, history of cholesterol, history of diabetes, history of smoking, history of blood pressure, marital status and number of family members) were used to collect data. Family Relations Index (Holohan \& Moss, 2004). The family relation index is one of the subsets of the overall family environment index (FES) includes 27 items. These items measure three family function index, namely, conflict (9 items), expression (9 items), and cohesion (9 items). All grades of this scale are based on a 5-degree spectrum (most often, almost always, Sometimes, rarely and almost never). The range of scores for each of these sub-scales is 9 to 45 . The validity and

Table I Comparison of case and control groups in terms of clinical demographic variables

\begin{tabular}{llll}
\hline Variables & $\begin{array}{l}\text { Patient group } \\
\text { number (Percent) }\end{array}$ & $\begin{array}{l}\text { Health group number } \\
\text { (Percent) }\end{array}$ & Statistical test \\
\hline $\begin{array}{l}\text { Education } \\
\text { Elementary }\end{array}$ & $(54) 27$ & $(8) 4$ & \\
High school & $(40) 20$ & $\mathrm{x}^{2}=29 / 36, \mathrm{P}=0 / 000$ \\
University & $(6) 3$ & $(38) 19$ & \\
History of high blood pressure & & $(54) 27$ & $\mathrm{Df}=2, \mathrm{x}^{2}=9 / 722, \mathrm{P}=0 / 002$ \\
Yes & $(42) 21$ & & \\
No & $(58) 29$ & $(14) 7$ & \\
History of Diabets & & $(86) 43$ & $\mathrm{Df}=2, \mathrm{x}^{2}=0 / 585, \mathrm{P}=0 / 444$ \\
\hline
\end{tabular}

reliability of this index have been confirmed by its developers. In the Holman and Mouse study, the reliability of the family relation index with the use of Cronbach's alpha for each dimension of the cohesion, expressiveness and conflict sub-scales were reported to be $0.87,0.68$, 0.78 , respectively.

In Iran, the scale of the family environment has been used by Farokhzad $^{12}$ and its validity and reliability have been high. In this research, the reliability of the family relation index by Cronbach's alpha method was 0.72 for consistency, 0.78 for expression, 0.68 for expression, and 0.72 for conflict. A higher score in each sub-scale indicates that it has a high-level feature. The total alpha value for this study was 0.76. Data after extracting, has been using software SPSS of Version 16. To describe the specimen specification were used frequency distribution and percentages. Also, for testing hypotheses, multivariate analysis of variance (MANOVA) was used to compare healthy and patient subjects in terms of the components of the family function index.

\section{Findings}

Based on the findings, the age range of the participants in the study was between 30 and 70 years old with an average of 50 years and a standard deviation of 8.96 years. Also, 50 percent of respondents were men and 50 percent were women. Table 1 shows the demographic and clinical characteristics of the participants in the study. Comparison of case and control group showed that there was a significant difference between the patient and the healthy group regarding age $(\mathrm{P}<0 / 0001)$, educational status $(\mathrm{P}<0 / 0001)$, smoking $(\mathrm{P}=0 / 002)$, history of blood pressure $(\mathrm{P}=0 / 05)$ and a history of heartburn $(\mathrm{P}<0 / 0001)$.

Using MANOVA Multivariate Analysis, the relation between family function index, was investigated cohesion, expressiveness and conflict with the risk of myocardial infarction. Table 2 shows that the value of $F=11 / 572$ is meaningful at the level of $P<0 / 01$. Also, the results of multivariate analysis of variance showed that there was a significant difference between two groups of patients with normal and healthy subjects, at least one of the variables of contradiction, expressiveness and coherence.

In the MANOVA analysis, comparison of patients and healthy subjects in terms of family performance index showed that there is a significant difference between the two groups of patients in terms of family solidarity index $(\mathrm{p}<0 / 01)$ and family conflict index $(\mathrm{P}<0 / 01)$, but There was no statistically significant difference between the two case and control groups in terms of expression (Table 3 ). 
Table Continued..

\begin{tabular}{|c|c|c|c|}
\hline Variables & $\begin{array}{l}\text { Patient group } \\
\text { number (Percent) }\end{array}$ & $\begin{array}{l}\text { Health group number } \\
\text { (Percent) }\end{array}$ & Statistical test \\
\hline Yes & $(22) I I$ & $(16) 8$ & \\
\hline No & (78)39 & $(84) 42$ & \\
\hline Smoking & & & $\mathrm{Df}=2, \mathrm{x}^{2}=3 / 843, \mathrm{P}=0 / 05$ \\
\hline Yes & $(22) । I$ & $(8) 4$ & \\
\hline No & (78)39 & $(92) 46$ & \\
\hline History of high cholesterol & & & $D f=2, x^{2}=2 / 852, P=0 / 091$ \\
\hline Yes & $(42) 21$ & $(26) 13$ & \\
\hline No & $(58) 29$ & $(74) 37$ & \\
\hline History of myocardial infarction & & & $\mathrm{Df}=2, \mathrm{x}^{2}=19 / .48, \mathrm{P}=0 / 000$ \\
\hline Yes & $(32) 16$ & $(0) 0$ & \\
\hline No & $(68) 34$ & $(100) 50$ & \\
\hline History of myocardial infarction in the family & & & $D f=2, x^{2}=0 / 6777, P=0 / 17$ \\
\hline Yes & $(34) 17$ & $(38) 19$ & \\
\hline No & (66)33 & (62)3I & \\
\hline
\end{tabular}

Table 2 Multivariate analysis of variance

\begin{tabular}{llllll}
\hline Title of exam & amount & F & $\begin{array}{l}\text { Degree of freedom of } \\
\text { hypothesis }\end{array}$ & $\begin{array}{l}\text { The wrong degree of } \\
\text { freedom }\end{array}$ \\
\hline The effect of a pillow test & $0 / 328$ & $1 \mathrm{I} / 572$ & 4 & 95 & $0 / 000$ \\
Lambda wicks & $0 / 672$ & $\mathrm{II} / 572$ & 4 & 95 & $9 / 000$ \\
Test of Hotelling Effect & $0 / 487$ & $\mathrm{II} / 572$ & 4 & 95 & $0 / 000$ \\
Roy's Test In largest Analysis & $0 / 487$ & $\mathrm{II} / 572$ & 4 & 95 & $0 / 000$
\end{tabular}

Table 3 Comparison of the patient and healthy group in terms of the risk of myocardial infarction

\begin{tabular}{|c|c|c|c|c|}
\hline Variables & Control group (healthy)Average deviation)) & Case group (patient)Average deviation)) & $\mathbf{F}$ & $\mathbf{P}$ \\
\hline Conflict & $(3 / 67) 26 / 24$ & $(2 / 88) 28 / 46$ & 20-Nov & $0 / 001$ \\
\hline Expressive & $(3 / 92) 32 / 70$ & $(3 / 52) 32 / 44$ & $0 /|2|$ & $0 / 728$ \\
\hline Coherence & $(3 / 89) 34 / 08$ & $(3 / 90) 30 / 02$ & $27 / 092$ & $0 / 000$ \\
\hline
\end{tabular}

\section{Discussion}

The purpose of this study was to investigate the relation between family function index and the risk of myocardial infarction. Considering to the results, there was a significant difference between the two groups of healthy and patients people in terms of insufficiency of family cohesion, in which the lack of coherence in the family was higher in the patient group. In the patient group, all the items in this variable were in the negative direction, and the individuals in this group actually had a low degree of cohesion. However, there were no deficiencies in the group of healthy people, or at least not severely in the patient group. Commitment components (such as the extent to which people are committed to neighborhood affairs and correctly play their role), the assistance and support of members towards each other (for example, how much a person tries to help other family members in the proper conduct of affairs), and, likewise, It was time and energy for each other, or empathy in affairs, the importance of the tastes and the will of others, and aligned with them in this sub-scale.

The results of some other studies have also been similar to the results of this study. For example, Peterson's research, ${ }^{13}$ Minuccin et al. ${ }^{14}$ Miuchen et al. ${ }^{15}$ Cheraghi et al. ${ }^{16}$ all of which are devastating effects on the inadequacy of family cohesion on individual health, therefore the positive effects of high coherence have been emphasized on their health. The lack of emotional support from family members and the lack of satisfaction of their emotional needs will damage the self-esteem of individuals. A low-integrity family environment is an environment in which people don't feel emotional security and do not meet their needs. In this case, the person suffers from a supportive emotional weakness and these factors increase the index of mental illness. For example, in the development of heart disease, the lack of family support can lead to nerve disorders in the individual, and this will affect the functioning of the heart's nervous system. When a person has low self-esteem, he saves it in secret, and the term selfmedication leads to secretion of hormones harmful to the heart and the future.

In this study, there was no relation between family history of infertility and myocardial infarction disorder. Patients and healthy group were in the same condition in terms of the level of expression 
in the family. Similar research has not been found in relation to the relation between expression and index of disease, but the relation between this variable and the occurrence of psychological and identity behaviors has been done by Gholizadeh et al. ${ }^{17}$ in which the effect of expression of individuals on the index Risky behaviors are emphasized. Expression, is the level of encouragement of family members, and the expressive expression of thoughts and feelings are more relevant; as long as feelings and emotions and opinions are expressed easily, therefore it will reduce the level of anxiety and stress of the individual. For example, fear of punishment and humiliation and lack of selfesteem and veil and pride for expressing and expressing emotions and thoughts can all be factors that ultimately lead to disturbances in the level of expression of the individual.

There was a significant difference in the relation between family conflict with myocardial infarction (MI) disorder in both groups. The group of patients was very different from the healthy group in terms of conflict in the family environment. For example, in the patient group responses, the issues that led to conflict in the family environment were very different from the healthy group. For example, the responses of the patients' group were well documented as controversial issues, and the individuals in the group referred to them fully and directly. But in the healthy group, the contributing factors were prohibited and destructed to the conflict. These components include inputs such as anger, violence and conflict among members (for example, throwing objects and expressing ugly words to the audience), their ethics and their mood in dealing with issues (such as how to deal with conversations and discuss different topics), The existence or absence of physical conflicts (such as beatings and conflicts) and the negotiation process to resolve the issues that led to the conflict. The results were consistent with other research findings ${ }^{18,19}$ that emphasized the negative effects of conflict on health and social behaviors.

In the above research, the process of conflict in the family could affect the health of individuals. For example, in conflicting situations, the individual with family members has experienced physical reactions, and that these reactions will be negative and harmful to the health of the person. The conflict component actually refers to the degree of anger, violence, and disagreement among family members. For example, the abundance of controversy, the throwing of devices in the anger or criticism time to each other is considered.

There are several explanations about the mechanism of family conflict effects on family members of heart disease. Equilibrium theory believes that the body struggle to balance itself in times of emotional state. Increased heart rate, muscle contraction and stiffening, increased blood pressure, pupil dilation, hand and foot chills, increased blood flow in large muscles, high sweating, decreased pain sensation and skin irritation from the effects of this condition. ${ }^{20}$ The other explanation states that family-specific events due to the parentchild's conflict can directly increase stress, which results in arousal of nervous, hormone, and immune systems, leading to a biological response in the body, and causes reactions such as increased heart rate, respiration, sugar and muscle. ${ }^{21}$

Except for the history of myocardial infarction in the family and the expression variable, all other variables (education, history of stroke, history of cholesterol, history of diabetes, history of smoking, history of blood pressure and conflict of mind, and coherence) with the dependent variable, has meaningful relation with the risk of myocardial infarction. Variables in this study have been evaluated in other studies. For example, some studies, such as, Khosravi et al., ${ }^{22}$ Foruzandeh et al., ${ }^{23}$ Heydari et al., ${ }^{24}$ Jalali nia, ${ }^{25}$ Dhooper, ${ }^{26}$ Campbell, ${ }^{27}$ vahedian Azimi et al. (2009) showed that the incidence of illness is highly correlated with family status. The results of the above-mentioned research indicate that the family status has been affected by the behavior of different physical and mental disorders, including mental illnesses, and in particular, cardiovascular diseases in individuals. Similarly, the results have been found in the effect of the index of family function on health in Holi, ${ }^{28}$ Hooley et al., ${ }^{29}$ Canther et al. ${ }^{30}$ For demographic variables, cessation behaviors such as smoking cessation were also studied in the study of Mermelstein et al., ${ }^{31}$ and for diabetes, in the studies of Klausner et al., ${ }^{32}$ as well as Minuchin Rosman et al..$^{15}$ The impact of blood pressure fluctuations has also been discussed in the study by Ewart et al. ${ }^{33}$ On the coherence and family affinities and the negative impact of their failure on the health of individuals, we can also point out the study of Weisman. ${ }^{34}$

The present study was confronted with limitations that should be considered in generalizing the results. One of these limitations is the size of the sample, which is relatively small. The reason for this is the difficulty of studying and patient samples (with a questionnaire) due to their physical condition. Therefore, other researchers will be asked to study more accurately the relation between family performance index and the risk of coronary artery atherosclerosis on more families (more patient samples) with non-questionnaires and more time spent. This study was conducted only on the two folks of Fars and Gilak, and the possibility of generalizing the results on other tribes would be limited to differences in cultures. To this end, investigators are recommended to explore other areas with influential cultural backgrounds. ${ }^{35}$ The present study was conducted on a cross-sectional basis; therefore, more in-depth studies are recommended due to the length of the process of development and the type of disease involved, which requires longitudinal studies and cohort studies. Working with families and understanding the depth of their relation requires the acquisition of special communication skills. The researchers are encouraged to learn these factors before starting the study. The most important application of the findings of this study is the use of results in educational interventions and guidance to family education.

\section{Conclusion}

Failure to family functioning index, means, cohesion and conflict in family relations, are among the factors influencing the index of myocardial infarction. The results of this study showed a significant difference between the two groups of patients and healthy in terms of conflict and coherence indices. If the degree of failure is higher, the risk of developing the disease increases. It is important to recognize the impact of these factors on preventing diseases for families, and reducing the gap between ignorance and the underlying condition of the disease. Given that families' access to such factors is not at a single level, facilitating access and providing a suitable platform for teaching and disseminating outcomes through inclusive media, health centers, etc., is essential and can ultimately lead to reducing the incidence of heart attacks for the Iranian population in the future.

\section{Acknowledgements}

None.

\section{Conflict of interest}

The author declares no conflict of interest. 


\section{References}

1. Mir Miran P, Baaygi F. Cardiovascular health. World of Nutrition Tehran Unilever Health Institute; 2005.

2. Williams J. American heart association: a review of the field; 2013.

3. Sharifi H. Psychosocial complications of coronary artery disease. Cardiac news; 2011.

4. Brunner Lillian Scholtis. Nursing Cardiovascular Diseases. Translators Mohsen Kafashi, et al, editors. Tehran: Publishing boshra; 2000.

5. Masoudnia I. Hostility, anger and the risk of coronary artery atherosclerosis. Journal of Shahid Sadoughi University of Medical Sciences Yazd. 2010;18(6):551-540.

6. Rajabi Gh, Chahardooli $\mathrm{H}$, Attari, et al. Investigating the relationship between family function and psychosocial social class of high schoo students in Malayer. Journal of Educational Sciences and Psychology. 2007;3(14):128-113.

7. Ewart CK, Taylor CB, Kraemer H, et al. Reducing blood pressure reactivity during interper-sonal conflict:effects of marital communication training. Behavior Therapy. 1984;15(5):473-484.

8. Kimhan CB, Bruce F. Chorpita, et al. The association between the quality of family relationships and child psychopathology. Thesis University of Hawa; 2004.

9. Surjit-Singh B, Dhooper. Coronary heart disease and family functioning. Journal of Social Ser-vice. 2008;7(2):19-38.

10. Carissa A, Rebecca C, Karen A. Psychosocial factors in the development of heart disease in women:current research and future direction. Psychosom Med. 2011;72(9):842-854.

11. Shelley ET, Barbara JL, Catarina I, et al. Relationship of early life stress and psycholog-ical functioning to adult c-reactive protein in the coronary artery risk development in young adults study. Biological Psychiatr. 2006;60(15):819-824.

12. Farokhzad P. The influence of family atmosphere on the child's psychological tendencies. Thought Magazine and Behavior in Clinical Psychology. 2008;9:48-41.

13. Patterson JM. Family resilience to the challenge of a child's disability. Pediatr Ann. 1991;20:491-499.

14. Minuchin S, Baker L, Rosman BL, et al. A conceptual model of psychosomatic illness in children. Family organization and family therapy. Archives of General Psychia-try. 1975;32(8):1031-1038.

15. Minuchin S, Rosman BL, Baker L. Psychosomatic families: Anorexia nervosa in context. Cam-bridge. Harvard University. Press, MA; 1978.

16. Cheraghi M, Hasanzadeh M. Relationship between family cohesion and coping strategies with stress in adolescent girls and boys. Second National Congress of Psychology-Family Psychology, Islamic Azad University of Marvdasht Branch; 2012. p.17-19.

17. Gholizade A, Dorosti F. The effect of group expression training on socia adjustment of runaway girls. Journal of Behavioral Sciences Research. 2005;5:15-11.
18. Gottman JM. What predicts divorce? The relationship between marital processes and marital out-comes. Lawrence, Hillsdale, NJ, USA: Erlbaum Associates; 1994.

19. Wellman B. psychosomatic disorders, translated by Najarian. Dehghani M. Dabagh B. Emissions publishing growth; 1996.

20. Samvat T, Hojjatzadeh A, Shams M, et al. Ways of Prevention and Control of Cardiovascular Diseases. Tehran: Young Publishing; 2012.

21. Mehrabi Galeshkalami P. Evaluation of perceived stress and self-efficacy in patients with chronic lower back pain. Master Thesis University of Guilan; 1390

22. Khosravi Z, Alizadeh Sahraei O. The relationship between Internet addiction and family functioning and mental health in students. Journal of Psychology. 2011;14:80-59.

23. Foruzandeh N, Delaram M, Nourian K, et al. Comparative styles of family functioning in psychiatric patients with different diagnosis. Journal of Behavioral Sciences. 1392;11(5):474-483.

24. Heydari H, Farhaninia M, Safdari M, et al. Relationship between family members' knowledge and performance in relation to a patient's heart attack. Cardiovascular Nursing Journal. 2013;1(3):30-24.

25. Jalali Nia S. Assessing patients' know ledge, attitude and practice with coronary artery diseases and one of their family's member about theraputic regimen advises. Faculty of Nursing and Midwifery, Master Thesis University of Medical Sciences; 1997.

26. Dhooper SSB, Coronary. Heart disease and family functioning. Journal of Social Service Re-search. 2008;7(2):19-38.

27. Campbell L. Improving health through family interventions. Journal of Pediatric Psychology. 2008;20:313-328.

28. Hooley JM. Expressed emotion- a review of the critical literature. Clinical Psychology. 1985;5(2):119-139.

29. Hooley JM, Orley J, Teasdale JD. Levels of expressed emotion and relapse in depressed pa-tients. Br J Psychiatry. 1986;148:642-647.

30. Kanter J, Lamb HR, Loeper C. Expressed emotion in families: a critical review. Hosp Community Psychiatry. 1987;38(4):374-380.

31. Mermelstein R, Lichtenstein E, McIntyre K. Partner support and relapse in smoking-cessation programs. Journal of Consulting Clinical Psychology. 1983;51(3):465-466.

32. Klausner EJ, Koenigsberg HW, Skolnick N, et al. Perceived familial criticism and glu-cose control in insulin-dependent diabetes mellitus. International Journal of Mental Health. 1995;24(2):64-75.

33. Ewart CK, Taylor CB, Kraemer HC, et al. High blood pressure and marital discord: not being nasty matters more than being nice. Health Psychology. 1991;10(3):155-163.

34. Weisman AG. Integrating culturally based approaches with existing interventions for Hispanic/Latino families coping with schizophrenia. Psychother Res Prac. 2005;42:178-197.

35. Majid A, Alhani F, Ahmadi F, et al. The impact of family-based empowerment pattern on the life of patients with acute myocardial infarction. Special Care Nursing Magazine. 1388;2(4):132-127. 